\title{
The Risk Factors and Incidence of Type 2 Diabetes Mellitus and Metabolic Syndrome in Women With Previous Gestational Diabetes
}

\author{
Majid Valizadeh ${ }^{1}$; Nooshin Alavi ${ }^{1}$; Saeideh Mazloomzadeh ${ }^{2}$; Zahra Piri ${ }^{3,{ }^{*}}$; Hamidreza \\ Amirmoghadami ${ }^{4}$ \\ ${ }^{1}$ Metabolic Disease Research Center, Zanjan University of Medical Sciences, Zanjan, IR Iran \\ ${ }^{2}$ Social Determinants of Health Research Center, Zanjan University of Medical Sciences, Zanjan, IR Iran \\ ${ }^{3}$ Student Research Committee, Zanjan University of Medical Sciences, Zanjan, IR Iran

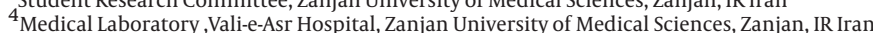 \\ *Corresponding author:Zahra Piri, Student Research Committee, Faculty of Medicine, Zanjan University of Medical Sciences, Zanjan, IR Iran. Tel: +98-9128205320, E-mail: zahra.piri@ \\ gmail.com
}

Received: July 2, 2014; Revised: September 19, 2014; Accepted: December 20, 2014

\begin{abstract}
Background: Gestational diabetes mellitus (GDM) affects nearly 5\% of pregnancies. Significant proportion of the women with previous GDM develops type 2 diabetes mellitus (T2DM) in the next years, which indicates a higher risk in them than in the general population. Objectives: We conducted this study to determine the risk factors and incidence of abnormal glucose level and metabolic syndrome (MetS) in women with a history of GDM in a long period after delivery in our region.

Patients and Methods: We extracted the demographic characteristics of 110 women with GDM who had delivered during 2004 - 2010 in three main hospitals of Zanjan City, Iran. The patients were recalled to perform oral glucose tolerance test(OGTT) and other necessary tests for MetS diagnosis. Anthropometric measurements were recorded of all the participants.

Results: In this study, 110 women with a history of GDM were studied at one to six years since delivery. Among these women, 36 (32.7\%) developed T2DM and 11 (10\%) had impaired fasting glucose (IFG) or impaired glucose tolerance (IGT). Moreover, 22 women (20\%) had developed MetS. among those with abnormal results in glycemic test, $93.6 \%$ had fasting blood sugar(FBS) $\geq 95 \mathrm{mg} / \mathrm{dL}(\geq 5.27 \mathrm{mmol} / \mathrm{L})$ at the time of GDM diagnosis in the index pregnancy that was significantly higher than the normal glycemic test (NGT) group with $42.9 \%$ being affected $(\mathrm{OR}, 19.55 ; \mathrm{P}<0.0001)$. There was a significant difference between those with abnormal results and NGT group in interval between delivery and performing laboratory tests $(27 \pm 18.8$ and $18.5 \pm 17.7$ months, respectively; $\mathrm{OR}, 1.02 ; \mathrm{P}=0.02)$. No insulin use during pregnancy was discovered as a protective factor in women with a history of $\operatorname{GDM}(\mathrm{OR}, 0.35 ; \mathrm{P}=0.01)$. Those with abnormal results were significantly different from NGT group in the number of parities ( $2.61 \pm 1.4 \mathrm{Vs} .2 .05 \pm 1.1$, respectively; $\mathrm{OR}, 1.4 ; \mathrm{P}=0.03$ ). The most common component of MetS among women with a history of GDM was FBS $>100 \mathrm{mg} / \mathrm{dL}(>5.55 \mathrm{mmol} / \mathrm{L})$.

Conclusions: Regarding the high incidence of the T2DM and MetS among women with a history of GDM, they should be screened at a regular interval for diabetes and other cardiovascular risk factors.
\end{abstract}

Keywords: Gestational Diabetes Mellitus; Metabolic Syndrome; Type 2 Diabetes Mellitus; Risk Factors

\section{Background}

Type 2 diabetes mellitus (T2DM) is a multifactorial and heterogeneous dysglycemic condition due to insulin deficiency of the pancreatic $\beta$ cells or insulin resistance of the glucose consumer cells (1). Gestational diabetes mellitus (GDM) is an impaired glucose tolerance (IGT) first diagnosed in pregnancy that can convert to T2DM as a major world health concern (2).

The GDM prevalence in the United States is about $14 \%$, which has been increased during last years due to obesity, fatty diets, and sedentary lifestyle (3-5). In Iran, approximately $4.8 \%$ of pregnancies become complicated with GDM (6). This incidence is not the same in different regions of the country; for example, this is higher in southern parts of Iran (8.9\%) (7).

The placental released factors during pregnancy such as human chorionic somatomammotropin (hCS), tumor necrosis factor $\alpha$, interleukin 6 , and leptin that induce insulin resistance and could lead to GDM (3).

Following delivery of placenta as a source of anti-insulin hormones, GDM would be mostly resolved. However, these patients will be at a higher risk for T2DM and metabolic syndrome (MetS) in the coming years $(2,8,9)$.

Generally, T2DM rate in women with previous GDM is about 3\% to 65\% (10). Women with a history of GDM are at seven-fold higher risk for developing T2DM in next years (11).

Considering the different follow-up time and many other factors, the risk of progressing to T2DM is different. In North America, T2DM incidence in women with previous GDM was $2 \%$ to $38 \%$ during one year of delivery, which is partially depended on ethnicity and severity of glucose intolerance during pregnancy $(12,13)$. These patients are

Copyright (C) 2015, Research Institute For Endocrine Sciences and Iran Endocrine Society. This is an open-access article distributed under the terms of the Creative Commons Attribution-NonCommercial 4.0 International License (http://creativecommons.org/licenses/by-nc/4.0/) which permits copy and redistribute the material just in noncommercial usages, provided the original work is properly cited. 
Valizadeh M et al.

being recognized to show a great tendency toward developing T2DM in following five years as well as in next ten years with a slower slope (4). In other studies, 33\% to 50\% of women with a history of GDM developed T2DM in following five years and 35\% to $60 \%$ of them in the next ten years (14).

Other risk factors in mothers with a history of GDM are caesarian delivery and preeclampsia. Their children's complications include congenital anomalies, macrosomia, and neonatal hypoglycemia (15).

There are several maternal risk factors for developing T2DM. Some of the known predicting factors include older maternal age (10), pre-pregnancy overweightness (16), after delivery high body mass index (BMI) (17-19) needed dose of insulin (20), severity of glucose imbalance during pregnancy (21), history of delivering macrosomic neonate (22), parity $>2(20,23)$, anti- $\beta$ cells anti-bodies in pancreas (24), GDM diagnosis at early pregnancy (25), elevated fasting blood sugar(FBS) or blood sugar in $75 \mathrm{~g}$ oral glucose tolerance test (OGTT) (18), low socio-economic status, and urban residence (10). In addition, weight gain between two pregnancies increases the risk of T2DM development $(26,27)$.

The worldwide increasing incidence of DM and MetS causes huge financial burden to the society. Identifying GDM as a "trigger" of T2DM and subsequently MetS in these patients and their offspring shows that their sugar must be controlled tightly (9).

Considering these complications of GDM, there are a small number of studies in developing countries that follow this target longer than a few weeks. The present study goal was to determine T2DM incidence and the related risk factors and MetS frequency after one to two years of delivery as a longer interval in the foresaid population.

\section{Objectives}

We conducted this study to determine the incidence and risk factors of developing T2DM, impaired glucose tolerance (IGT) or impaired fasting glucose (IFG), and MetS among women with previous GDM in one to six years after delivery.

\section{Patients and Methods}

\subsection{Patients}

In the present study, we extracted the demographic characteristics of women with a history of GDM who were visited and followed in the Endocrinology Clinic of a teaching hospital in Zanjan Province, Iran. All women with a history of GDM who had delivered during 2004 - 2010 in three main hospitals in Zanjan were called to perform laboratory tests and to collect the clinical information. A total of 165 women were called and finally, 110 women with a history of GDM accepted to participate in the study.

\subsection{Measurements}

Anthropometric characteristics including height(using stadiometer), and weight (using Seca scale with the least clothing) were measured. Thereafter, BMI was calculated for all the cases. Waist circumference (WC) was measured at the middle of the subcostal area and the iliac crest with a plastic measure tape. The sedentary blood pressure (BP) was measured by analog sphygmomanometer after five minutes rest.

\subsection{Laboratory Data}

After at least 12 to 14 hours of fasting, the participants were referred to the predetermined laboratory to draw the blood sample and test for the FBS, OGTT, lipids, and glycosylated hemoglobin $\left(\mathrm{HbA}_{1} \mathrm{C}\right)$. Obviously, the known cases of T2DM were not tested for glucose tolerance.

The FBSlevels $\geq 126 \mathrm{mg} / \mathrm{dL}$ ( $\geq 6.99 \mathrm{mmol} / \mathrm{L}$ ) or BS $\geq 200$ $\mathrm{mg} / \mathrm{dL}$ ( $\geq 11.10 \mathrm{mmol} / \mathrm{L}$ ) after two hours OGTT established the diagnosis of diabetes. FBS between 100 to $126 \mathrm{mg} / \mathrm{dL}$ (5.5-6.99 $\mathrm{mmol} / \mathrm{L}$ ) was defined as IFG and the blood sugar level of 140 to $199 \mathrm{mg} / \mathrm{dL}$ (7.77-11.04 mmol/L) in OGTT was defined as IGT. According to the Iranian National Committee of Obesity criteria, MetS was defined as having any three of the following traits: $\mathrm{WC}>95 \mathrm{~cm}$ in females; triglyceride (TG) $\geq 150 \mathrm{mg} / \mathrm{dL}(>1.70 \mathrm{mmol} / \mathrm{L}$ ) or drug consumption for elevated TG levels; high-density lipoprotein (HDL) $<50 \mathrm{mg} / \mathrm{dL}(<1.30 \mathrm{mmol} / \mathrm{L})$; systolic BP $\geq 130$ and/ or diastolic BP $\geq 85 \mathrm{~mm} \mathrm{Hg}$ or receiving antihypertensive drugs; and FBS $\geq 100 \mathrm{mg} / \mathrm{dL}$ ( $\geq 5.55 \mathrm{mmol} / \mathrm{L}$ ) or consuming antiglycemic agents (28).

\subsection{Statistical Analysis}

Values were expressed as mean \pm standard deviation (SD), and number (percentage), as appropriate. Comparisons were performed by independent-samples t-test for continuous variables and Chi square test for categorical variables. Logistic regression models were used to evaluate the association between GDM and study variables and the dependent variable was a combined variable of IFG, IGT, and DM.

Analysis of the data was performed by SPSS 16.0 (SPSS Inc, Chicago, Illinois, the United States). This study was approved by the ethic committee of Zanjan University of Medical Sciences. The written informed consent was obtained from all of the participants.

\section{Results}

In this study, 110 women with a history of GDM with a mean period of $22.8 \pm 1.92$ months since delivery were included. Thirty-six women (32.7\%) had developed T2DM; 11 (10\%) IFG (one woman) or IGT (10 women). Moreover, 22 women (20\%) had developed with MetS.

Women without normal results in glucose tolerance test (Non-NGT) had a mean BMI of that was higher than that of NGT group; however, the difference was not 
Valizadeh M et al.

statistically significant $(\mathrm{P}=0.09)$ (Table 1$)$. In non-NGT group, $72 \%$ of women were $>34$ years old which was not statistically significant $(P=0.17)$ in comparison with NGT group (60\%). Women in the Non-NGT group required a larger amount of insulin during pregnancy than the NGT group did but the difference was not statistically significant different ( $34 \pm 24.3$ vs $25 \pm 14.4$ units/day; $\mathrm{P}=0.06$ ). The Non-NGT group had a significantly longer interval between delivery and laboratory tests $(\mathrm{OR}, 1.02 ; \mathrm{P}=0.02)$. In Non-NGT group, $93.6 \%$ had FBS $\geq 95 \mathrm{mg} / \mathrm{dL}$ ( $\geq 5.27 \mathrm{mmol} / \mathrm{L}$ ) at the time of performing OGTT that was significantly higher than that of the NGT group (42.9\%) (OR, 19.55; $\mathrm{P}<0.0001)$. No insulin use during pregnancy was demonstrated as a protec- tive factor in women with a history of GDM (OR, 0.35; $\mathrm{P}=0.01$ ).

There was no significant difference in maternal weight, WC, family history of DM, and history of macrosomic or large for gestational age neonate between two groups. The Non-NGT participants were significantly different with NGT in the number of parities $(2.61 \pm 1.4$ and 2.05 \pm 1.1 , respectively; $\mathrm{OR}, 1.41 ; \mathrm{P}=0.03)$. According to Table 2 only the FBS $\geq 95$ ( $\geq 5.27 \mathrm{mmol} / \mathrm{L}$ ) at the time of OGTT in the index pregnancy had a significant association with developing abnormal glycemic test in the multivariate analysis (OR, 20.55; P < 0.0001). As shown in Figure 153\% of the patientshadFBS $\geq 100 \mathrm{mg} / \mathrm{dL}(\geq 5.55 \mathrm{mmol} / \mathrm{L})$ as the most frequent component of MetS.

\begin{tabular}{|c|c|c|c|c|}
\hline Variables & NGT ${ }^{b}$ & Non NGT ${ }^{b}$ & OR $(95 \% \mathrm{CI})$ & P Value \\
\hline Maternal weight, $\mathrm{kg}$ & $71 \pm 11.5$ & $74 \pm 11.3$ & $1.02(0.98-1.05)$ & 0.23 \\
\hline BMI, $\mathrm{kg} / \mathrm{m}^{2}$ & $28 \pm 4.0$ & $29 \pm 4.1$ & $1.09(0.98-1.21)$ & 0.09 \\
\hline Waist circumference, $\mathrm{cm}$ & $92 \pm 11.9$ & $95 \pm 8.8$ & $1.02(0.98-1.06)$ & 0.18 \\
\hline Neonatal birth weight, $g$ & $3362 \pm 624$ & $3242 \pm 663$ & $1.00(0.99-1.00)$ & 0.36 \\
\hline Parity, No. & $2.05 \pm 1.1$ & $2.61 \pm 1.4$ & $1.41(1.03-1.94)$ & 0.03 \\
\hline Delivery and follow-up lab test interval, mo & $18.5 \pm 17.7$ & $27 \pm 18.8$ & $1.02(1.00-1.04)$ & 0.02 \\
\hline Age $>34 y$ & & & & 0.17 \\
\hline Yes & $37(59.7)$ & $34(72.3)$ & $1.76(0.78-3.99)$ & \\
\hline No & $25(40.3)$ & $13(27.7)$ & 1.00 & \\
\hline Family history of diabetes mellitus & & & & 0.62 \\
\hline Yes & $23(36.5)$ & $15(31.9)$ & 1.00 & \\
\hline No & $40(63.5)$ & $32(68.1)$ & $0.82(0.37-1.81)$ & \\
\hline FBS $\geq 95 \mathrm{mg} / \mathrm{dL}(\geq 5.27 \mathrm{mmol} / \mathrm{L})$ & & & & $<0.0001$ \\
\hline Yes & $27(42.9)$ & 44 (93.6) & $19.55(5.4-69.74)$ & \\
\hline No & $36(57.1)$ & $3(6.4)$ & 1.00 & \\
\hline History of delivering macrosomic neonate & & & & 0.42 \\
\hline Yes & $3(4.8)$ & $4(8.7)$ & 1.00 & \\
\hline No & $59(95.2)$ & $42(91.3)$ & $0.53(0.11-2.51)$ & \\
\hline Insulin use & & & & 0.01 \\
\hline Yes & $37(58.7)$ & $37(80.4)$ & 1.00 & \\
\hline No & $26(41.3)$ & $9(19.6)$ & $0.35(0.14-0.83)$ & \\
\hline
\end{tabular}

a Abbreviations: BMI, body mass index; FBS, fasting blood glucose; and NGT, normal glycemic test.

$\mathrm{b}$ Data are presented as mean \pm SD or No. (\%).

Table 2. The Multivariate Analysis of Target Risk Factors

\begin{tabular}{lcc}
\hline Variable & OR $(\mathbf{9 5} \% \mathbf{C I})$ & P Value \\
\hline Parity & $1.40(0.97-2.17)$ & 0.33 \\
Delivery and follow-up lab test interval, months & $1.02(0.99-1.05)$ & 0.10 \\
FBS $\geq \mathbf{9 5} \mathbf{~ m g / d L}(\geq \mathbf{5 . 2 7} \mathbf{~ m m o l} / \mathbf{L})$ & $20.55(5.19-81.31)$ & $<0.0001$ \\
\hline
\end{tabular}


Valizadeh $M$ et al.

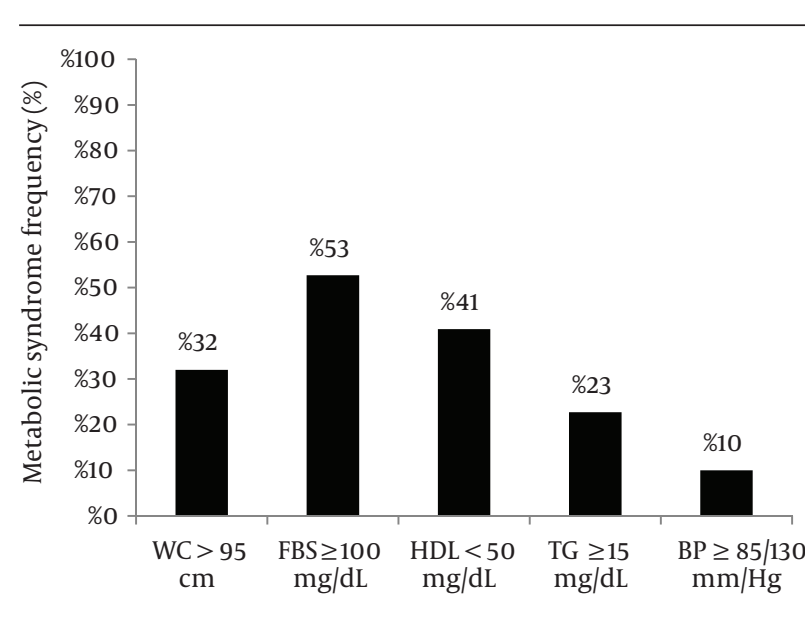

Figure 1. Frequency of Metabolic Syndrome Components in the Patients With Previous Gestational Diabetes Mellitus

\section{Discussion}

Of the 110 studied women with a history of GDM, onethird had developed T2DM and one-fifth MetS according to the Iranian National Committee of Obesity on average 23 months postpartum, which were higher than that expected rates. In the univariate analysis, the risk factors for developing T2DM included FBS $\geq 95 \mathrm{mg} / \mathrm{dL}$ ( $\geq 5.27$ $\mathrm{mmol} / \mathrm{L}$ ) at the time of GDM diagnosis, interval between delivery and follow-up lab test, and need to insulin therapy during pregnancy; however, in the multivariate analysis, FBS $\geq 95 \mathrm{mg} / \mathrm{L}(\geq 5.27 \mathrm{mmol} / \mathrm{L}$ ) was expressed to be the only risk factor.

Russell et al. study in Canada reported the cumulative incidence of T2DM at one, five, and ten years of previous delivery to be $5.9 \%, 14.8 \%$, and $22.2 \%$, respectively. In this retrospective cohort study the risk factors for developing T2DM included a pre-pregnancy weight $>86 \mathrm{~kg}(\mathrm{RR}=1.8$; $95 \% \mathrm{CI}, 1.2-2.9)$, need to insulin therapy during pregnancy ( $\mathrm{RR}=4.1 ; 95 \% \mathrm{CI}, 2.1-7.9)$, a pregnancy following the GDM $(\mathrm{RR}=2.3 ; 95 \% \mathrm{CI}, 1.6-3.4)$, and neonatal hypoglycemia (RR $=2.6 ; 95 \% \mathrm{CI}, 1.6-4.2)$. The T2DM incidence after ten years in Russell et al. study was less than that in our study with a shorter follow-up period. Our investigation showed a higher incidence of T2DM in women with history of previous GDM (29). This remarkable difference may refer to the demographic variables of the studied groups, which was nulliparous women with a mean age of 28 years old with $4 \%$ needing insulin therapy in the Canadian study versus multiparous with the mean age of 32 years old with $>65 \%$ needing insulin therapy (more severe GDM) in our study.

Lauenborg et al. study on a Danish population after median of 9.8 years of the index pregnancy reported diabetes and IFG/IGT incidence to be $40.0 \%$ and $27.0 \%$, respectively. They found pre-pregnancy overweightness and postpartum IGT were independently associated with increased risk of DM (30). The rate of T2DM in their study was lower than the rate in our study due to different follow-up periods. In addition, they presented different predictors for progressing to DM.

In a systematic review by Kim et al. the cumulative incidence of diabetes was reported to range from $2.6 \%$ to $70 \%$ in the studies with different follow-up periods ( 6 weeks to 28 years). They deducted steeper slope in incidence of T2DM in the five versus ten years of delivery. The elevated FBS during pregnancy was identified as a risk for future DM (4), which was similar to our study.

Comparing with the foresaid studies, the T2DM rate in our observed population was relatively high. This result might be related to ethnicity; however, we cannot disregard the influence of referral bias in our study. Our patients were recruited from a tertiary center that women with severe GDM were more likely to be referred to while the mild cases are handled by the obstetricians. Girgis et al. studied the ethnicity role in T2DM following GDM at mean period of 5.5 years after delivery. The South Asian women were at a higher risk to progress to abnormal GTT (69\%) than other ethnicities $(\mathrm{P}<0.05)$ (31).

An Iranian study by Tehrani et al. followed patients from Tehran Lipid and Glucose Study (TLGS) up to nine years after delivery. This investigation reported a higher rate of T2DM in women with a history of GDM (27.3\%) than women in control group (9.5\%) $(\mathrm{P}<0.001)$. However, number of women with a history of GDM was small ( 29 women) compared with control group (628 women) (32).

The role of ethnicity was remarked by Kousta et al. study (33). They studied on three groups of European, AsianIndian, and African-Caribbean women with a history of GDM. Considering the incidence of DM being respectively 28\%, 44\%, and 50\% in European, Asian-Indian, and African-Caribbean, there is a significant need for DM prevention and control plans in non-European women (18, 33). Breastfeeding for at least three months after delivery remarkably lowers the risk of T2DM among women with a history of GDM (2).

One-fifth (20\%) of the participants in our study had developed MetS during a mean postpartum period of 22.8 \pm 1.92 months. Retnakaran et al. studied the rate of MetS three months postpartum among three groups of women with NGT, gestational IGT, and GDM. The International Diabetes Federation defined MetS incidence was remarkably higher in both GDM (20.0\%) and GIGT (17.6\%) than in NGT women (10.0\%) (Overall P $=0.016)$. Abnormal WC was more frequent component of MetS, which was in accordance with our study (34). Moreover, in the Kousta et al. study, MetS was seen in $49 \%, 43 \%$, and $28 \%$ of Asian-Indian, African-Caribbean, and European women, respectively (33).

Parity $\geq 4$, FBS $\geq 95 \mathrm{mg} / \mathrm{dL}$ ( $\geq 5.27 \mathrm{mmol} / \mathrm{L}$ ) at the time of diagnosing GDM, and need to insulin therapy during pregnancy were the most important risk factors for developing DM. Moreover, Oldfield et al. indicated the pregnancy weight, older maternal age at follow up, enhancing the hyperglycemia, and high amount of insulin 
Valizadeh $M$ et al.

needed during pregnancy as the risk factors of developing T2DM (35).

Our study has several limitations. The sample size was relatively small and the referral bias had probably affected the incidence of T2DM. The advantages of this study were longer period of the follow-up (mean $22.8 \pm 1.92$ months) than previous studies in Iran and identification the MetS rate in the mentioned population. Future population based studies in Iran with longer follow-up period would more comprehensively clarify the predictors of developing T2DM in women with a history of GDM.

Our findings showed that a large number of women with a history of GDM develop T2DM and glucose intolerance in the following years. In addition, a remarkable percentage of these patients will develop cardiovascular diseases risk factors because of MetS. Therefore, women with a history of GDM should be screened after the appropriate period from delivery in order to discover the women with abnormal glucose tolerance and MetS for the primary necessary interventions.

\section{Acknowledgements}

We thank the patients who participated in this study.

\section{Authors' Contributions}

Majid Valizadeh developed the main idea and provided the opportunity for studying the mentioned patients. He supervised the study, data drafting, and final revision of the manuscript. Nooshin Alavi recalled the patients and gathered the data. Statistical analysis was done by Saeideh Mazloomzadeh. Zahra Piri did the transcription of the manuscript and data drafting. Hamidreza Amirmoghadami supervised the laboratory tests.

\section{Funding/Support}

The vice chancellor for Research of Zanjan University of Medical Sciences provided the necessary equipment for the anthropometric measurements and financial support of the laboratory tests.

\section{References}

1. Polonsky KS. The past 200 years in diabetes. $N$ Engl $\mathrm{J}$ Med. 2012;367(14):1332-40.

2. Ziegler AG, Wallner M, Kaiser I, Rossbauer M, Harsunen MH, Lachmann L, et al. Long-term protective effect of lactation on the development of type 2 diabetes in women with recent gestational diabetes mellitus. Diabetes. 2012;61(12):3167-71.

3. Metzger BE, Buchanan TA, Coustan DR, de Leiva A, Dunger DB, Hadden DR, et al. Summary and recommendations of the Fifth International Workshop-Conference on Gestational Diabetes Mellitus. Diabetes Care. 2007;30 Suppl 2:S251-60.

4. Kim C, Newton KM, Knopp RH. Gestational diabetes and the incidence of type 2 diabetes: a systematic review. Diabetes Care. 2002;25(10):1862-8.

5. James DK. High Risk Pregnancy: Management Options. 3rd edPhiladelphia: Saunders/Elsevier; 2006.

6. Keshavarz M, Cheung NW, Babaee GR, Moghadam HK, Ajami ME, Shariati M. Gestational diabetes in Iran: incidence, risk factors and pregnancy outcomes. Diabetes Res Clin Pract. 2005;69(3):279-86.
7. Hadaegh F, Tohidi M, Harati H, Kheirandish M, Rahimi S. Prevalence of gestational diabetes mellitus in southern Iran (Bandar Abbas City). Endocr Pract. 2005;11(5):313-8.

8. Bellamy L, Casas JP, Hingorani AD, Williams D. Type 2 diabetes mellitus after gestational diabetes: a systematic review and meta-analysis. Lancet. 2009;373(9677):1773-9.

9. Xu Y, Shen S, Sun L, Yang H, Jin B, Cao X. Metabolic syndrome risk after gestational diabetes: a systematic review and meta-analysis. PLoS One. 2014;9(1).

10. Feig DS, Zinman B, Wang X, Hux JE. Risk of development of diabetes mellitus after diagnosis of gestational diabetes. CMAJ. 2008;179(3):229-34.

11. Dasgupta K, Da Costa D, Pillay S, De Civita M, Gougeon R, Leong A, et al. Strategies to optimize participation in diabetes prevention programs following gestational diabetes: a focus group study. PLoS One. 2013;8(7).

12. Metzger BE, Bybee DE, Freinkel N, Phelps RL, Radvany RM, Vaisrub N. Gestational diabetes mellitus. Correlations between the phenotypic and genotypic characteristics of the mother and abnormal glucose tolerance during the first year postpartum. Diabetes. 1985;34 Suppl 2:111-5.

13. Dacus JV, Meyer NL, Muram D, Stilson R, Phipps P, Sibai BM. Gestational diabetes: postpartum glucose tolerance testing. Am J Obstet Gynecol.1994;171(4):927-31.

14. Shyam S, Arshad F, Abdul Ghani R, Wahab NA, Safii NS, Nisak MY, et al. Low glycaemic index diets improve glucose tolerance and body weight in women with previous history of gestational diabetes: a six months randomized trial. Nutr J.2013;12:68.

15. Chamberlain C, McNamara B, Williams ED, Yore D, Oldenburg B, Oats J, et al. Diabetes in pregnancy among indigenous women in Australia, Canada, New Zealand and the United States. Diabetes Metab Res Rev. 2013;29(4):241-56.

16. Coustan DR, Carpenter MW, O'Sullivan PS, Carr SR. Gestational diabetes: predictors of subsequent disordered glucose metabolism. Am J Obstet Gynecol. 1993;168(4):1139-44.

17. Grant PT, Oats JN, Beischer NA. The long-term follow-up of women with gestational diabetes. Aust N Z J Obstet Gynaecol. 1986;26(1):17-22.

18. Steinhart JR, Sugarman JR, Connell FA. Gestational diabetes is a herald of NIDDM in Navajo women. High rate of abnormal glucose tolerance after GDM. Diabetes Care.1997;20(6):943-7.

19. Kaufmann RC, Schleyhahn FT, Huffman DG, Amankwah KS. Gestational diabetes diagnostic criteria: long-term maternal followup. Am J Obstet Gynecol. 1995;172(2 Pt 1):621-5.

20. Lee AJ, Hiscock RJ, Wein P, Walker SP, Permezel M. Gestational diabetes mellitus: clinical predictors and long-term risk of developing type 2 diabetes: a retrospective cohort study using survival analysis. Diabetes Care. 2007;30(4):878-83.

21. Catalano PM, Vargo KM, Bernstein IM, Amini SB. Incidence and risk factors associated with abnormal postpartum glucose tolerance in women with gestational diabetes. Am J Obstet Gynecol. 1991;165(4 Pt 1):914-9.

22. Larsson G, Spjuth J, Ranstam J, Vikbladh I, Saxtrup O, Astedt B. Prognostic significance of birth of large infant for subsequent development of maternal non-insulin-dependent diabetes mellitus: a prospective study over 20-27 years. Diabetes Care. 1986;9(4):359-64.

23. Kritz-Silverstein D, Barrett-Connor E, Wingard DL. The effect of parity on the later development of non-insulin-dependent diabetes mellitus or impaired glucose tolerance. $N$ Engl J Med. 1989;321(18):1214-9.

24. de Leiva A, Mauricio D, Corcoy R. Diabetes-related autoantibodies and gestational diabetes. Diabetes Care. 2007;30 Suppl 2:S127-33.

25. Kjos SL, Buchanan TA, Greenspoon JS, Montoro M, Bernstein GS, Mestman JH. Gestational diabetes mellitus: the prevalence of glucose intolerance and diabetes mellitus in the first two months post partum. Am J Obstet Gynecol. 1990;163(1 Pt1):93-8.

26. Linne Y, Barkeling B, Rossner S. Natural course of gestational diabetes mellitus: long term follow up of women in the SPAWN study. BJOG. 2002;109(11):1227-31.

27. Peters RK, Kjos SL, Xiang A, Buchanan TA. Long-term diabetogenic effect of single pregnancy in women with previous gestational diabetes mellitus. Lancet. 1996;347(8996):227-30. 


\section{Valizadeh $M$ et al.}

28. Azizi F, Hadaegh F, Khalili D, Esteghamati A, Hosseinpanah F, Delavari A, et al. Appropriate definition of metabolic syndrome among Iranian adults: report of the Iranian National Committee of Obesity. Arch Iran Med. 2010;13(5):426-8.

29. Russell C, Dodds L, Armson BA, Kephart G, Joseph KS. Diabetes mellitus following gestational diabetes: role of subsequent pregnancy. BJOG. 2008;115(2):253-9.

30. Lauenborg J, Hansen T, Jensen DM, Vestergaard H, Molsted-Pedersen L, Hornnes P, et al. Increasing incidence of diabetes after gestational diabetes: a long-term follow-up in a Danish population. Diabetes Care. 2004;27(5):1194-9.

31. Girgis CM, Gunton JE, Cheung NW. The influence of ethnicity on the development of type 2 diabetes mellitus in women with gestational diabetes: a prospective study and review of the literature. ISRN Endocrinol. 2012;2012:341638.
32. Tehrani FR, Hashemi S, Hasheminia M, Azizi F. Follow-up of women with gestational diabetes in the Tehran Lipid and Glucose Study (TLGS): a population-based cohort study. J Obstet Gynaecol Res. 2012;38(4):698-704.

33. Kousta E, Efstathiadou Z, Lawrence NJ, Jeffs JA, Godsland IF, Barrett SC, et al. The impact of ethnicity on glucose regulation and the metabolic syndrome following gestational diabetes. Diabetologia. 2006;49(1):36-40.

34. Retnakaran R, Qi Y, Connelly PW, Sermer M, Zinman B, Hanley AJ. Glucose intolerance in pregnancy and postpartum risk of metabolic syndrome in young women. J Clin Endocrinol Metab. 2010;95(2):670-7.

35. Oldfield MD, Donley P, Walwyn L, Scudamore I, Gregory R. Long term prognosis of women with gestational diabetes in a multiethnic population. Postgrad Med J. 2007;83(980):426-30. 